\title{
Are men at greater risk for Parkinson's disease than women?
}

\author{
G F Wooten, L J Currie, V E Bovbjerg, J K Lee, J Patrie
}

J Neurol Neurosurg Psychiatry 2004;75:637-639. doi: 10.1136/jnnp.2003.020982

Parkinson's disease seems to occur more commonly in men than women based primarily on studies of death rates and prevalence. In recent years, several population based incidence studies of Parkinson's disease that included sex data have been conducted in a variety of populations around the world. To investigate whether these incidence studies suggest an increased risk of Parkinson's disease in men, a meta-analysis was performed of the differences in incidence of Parkinson's disease between men and women reported in seven studies that met the inclusion criteria. A significantly higher incidence rate of Parkinson's disease was found among men with the relative risk being 1.5 times greater in men than women. Possible reasons for this increased risk of Parkinson's disease in men are toxicant exposure, head trauma, neuroprotection by oestrogen, mitochondrial dysfunction, or $\mathrm{X}$ linkage of genetic risk factors.

W hether there is a sex difference in risk for Parkinson's disease (PD) is controversial. ${ }^{1} \mathrm{PD}$ seems to occur more commonly in men than women based primarily on studies of death rates and prevalence. ${ }^{12}$ Death rates, however, do not accurately reflect the incidence of $\mathrm{PD}^{3}$ because of inaccurate diagnoses on death certificates. Likewise, prevalence data are problematic. ${ }^{1}$ Prevalence studies are subject to potential sex differences in survival, access to health care, access to the system whereby cases were ascertained for inclusion in the study, and sex differences in the underlying population. ${ }^{1}$

Because incidence of PD represents the number of new cases developed or diagnosed during a specific time interval within a predefined population at risk, incidence measurements are more direct and unambiguous epidemiological estimates of risk for developing PD than are death rates or prevalence. Incidence data from well defined populations obviate a number of concerns with prevalence data, such as differential mortality between men and women.

In recent years, several population based incidence studies of PD that included sex data have been conducted in a variety of populations around the world. To determine whether these incidence studies suggest an increased risk of PD in men, we performed a meta-analysis of the differences in incidence of PD between men and women reported in these studies.

\section{METHODS}

The Medline database was searched for population based ascertainment studies of PD average annual incidence rates adjusted for sex and age. The studies included in our metaanalysis met six criteria: (1) The study must have been published after 1980. Inclusion of studies published before 1980 would lead to the inclusion of neurodegenerative disorders that would be recognised now as not being PD (for example, progressive supranuclear palsy, multiple system atrophy, etc). Also, older studies are more likely to be contaminated with cases of post-encephalitic parkinsonism than studies published after 1980; (2) studies must have excluded secondary and/or drug induced parkinsonism; (3) studies must have ascertained at least 50 cases of PD; (4) the reported data must have included the sex of the probands and been expressed as age adjusted data; (5) studies must have ascertained all age groups - that is, there must be no age criteria for inclusion; and (6) ascertained cases must have been based on general population counts rather than age stratified sampling. Seven studies met all inclusion criteria. ${ }^{4-10}$

\section{Statistical analysis}

Meta-analyses were performed to determine whether there was a difference in PD incidence between men and women. Two population parameters were statistically analysed: the population incidence of $\mathrm{PD}$, and the population age adjusted incidence ratio. To determine whether the incidence of PD was similar among the men and women in the seven populations we used a Mantel-Haenszel test ${ }^{11}$ to test the null hypothesis that the ratio of the common odds for the incidence of PD among men and women was equal to 1 . To determine whether the age adjusted incidence of PD was similar among men and women we used a non-parametric Wilcoxon rank sum test to test the null hypothesis that the median age adjusted incidence ratio (male/female) was equal to $1 .{ }^{12} \mathrm{~A}$ bootstrap re-sampling procedure ${ }^{13}$ was used to construct $95 \%$ confidence limits for the median age adjusted incidence ratio.

\section{RESULTS}

Table 1 shows the average annual incidence rates per 100000 population adjusted for sex and age for the seven studies meeting our inclusion criteria. The weighted mean male to female ratio was 1.49 .

Using the Mantel-Haenszel test within these study populations, the odds of a man being affected with PD, $\grave{\mathrm{e}}_{\mathrm{MH}}=$ common odds ratio (male/female), was 1.17 (95\% CL ( 1.07 to 1.28$\left.), \chi_{\text {obs }}^{2}=11.22 ; \mathrm{p}=0.0008\right)$ times the odds of a woman being affected. Note that 1.17 is not an age adjusted ratio (that is, it is unweighted). Therefore, the relative incidence rate ratio of men to women of 1.49 more closely reflects the relative rates of $\mathrm{PD}$ occurrence between the sexes in the datasets that we have included in this metaanalysis.

Table 2 shows the data for the Wilcoxon rank sum test. Age adjusted incidence of PD using the Wilcoxon rank sum test was greater for men than women; the median of the age adjusted incidence ratios (men/women) was 1.49 (95\% CL 1.24 to $1.95, \mathrm{p}=0.031$ ).

Based on these statistical tests a significantly higher incidence rate of PD was found among men with the relative risk being 1.5 times greater in men than women. 
Table 1 Average annual incidence rates per 100000 population adjusted for sex and age

\begin{tabular}{|c|c|c|c|c|c|c|c|}
\hline Author(ref) & Site & Year & $\begin{array}{l}\text { Number of cases } \\
\text { ascertained }\end{array}$ & $\begin{array}{l}\text { Number of } \\
\text { M/F }\end{array}$ & Population sampled M/F & $\begin{array}{l}\text { Age adjusted incidence } \\
\text { per } 100000 \\
\text { population/y (M/F) }\end{array}$ & $\begin{array}{l}M / F \text { ratio (weighted } \\
\text { mean }=1.49 \text { ) }\end{array}$ \\
\hline Wender (4) & Poznan, Poland & 1989 & 159 & $78 / 81$ & $625506 / 672629$ & $13 / 10$ & 1.30 \\
\hline Wang $(5)^{*}$ & $\begin{array}{l}\text { China, } 29 \\
\text { provinces }\end{array}$ & 1991 & 566 & $327 / 239$ & $1936717 / 1932445$ & $2.1 / 1.7$ & 1.24 \\
\hline Granieri (6) & Ferrara, Italy & 1991 & 394 & $175 / 219$ & $89429 / 97952$ & $9.32 / 10.65$ & 0.88 \\
\hline Kuopio (7) & $\begin{array}{l}\text { Southwestern } \\
\text { Finland }\end{array}$ & 1999 & 385 & $187 / 198$ & $92250 / 104614$ & $21.5 / 11.0$ & 1.95 \\
\hline Vines (8) & Navarre, Spain & 1999 & 96 & $63 / 33$ & $259870 / 263693$ & $10.1 / 4.9$ & 2.06 \\
\hline Bower (9) & $\begin{array}{l}\text { Olmsted County, } \\
\text { MN }\end{array}$ & 1999 & 154 & $89 / 65$ & $682764 / 741710$ & $13.0 / 8.8$ & 1.48 \\
\hline Mayeux (10) & $\begin{array}{l}\text { Northern } \\
\text { Manhattan, NY }\end{array}$ & 1991 & 83 & $36 / 47$ & $72807 / 110127$ & $17.1 / 11.3$ & 1.51 \\
\hline
\end{tabular}

\section{DISCUSSION}

Our meta-analysis of seven studies of PD incidence meeting stringent criteria suggests that men are at greater risk for PD than women. Incidence rates adjusted for sex and age control for confounding factors in both prevalence and death rate studies. In particular, incidence studies minimise both the effects of sex differences in the populations from which the subjects are ascertained, a problem with prevalence studies, and the inaccuracy of death certificates, a problem with death rates. Technically, one of the least biased ascertainment methods would be a door to door survey. Only one of the studies included in our analysis used door to door ascertainment methods. Thus, potential bias in ascertainment methods and case identification must be considered for the other six studies. In none of the seven studies included in our meta-analysis were all subjects directly contacted by the investigators. Finally, we used the age adjusted rates provided by each of the studies. While it is probable that the various authors used standard methods for adjusting, it is also probable that several adjustment methods were used, and the differences in these methods may have resulted in different study specific rates than if unadjusted data from each study had been age adjusted by a uniform method.

Several recent incidence studies failed to meet our inclusion criteria. In 1984, Rajput et al reported sex specific incidence of parkinsonism from Olmstead County, Minnesota. ${ }^{14}$ Though the average annual age and sex specific incidence rates were higher for men in every decade of life, the authors explicitly included several types of parkinsonism including idiopathic PD, drug induced parkinsonism, and other parkinson-plus syndromes. In 1995, an incidence study of PD as part of the Rotterdam study was published in abstract form. ${ }^{15}$ These authors reported a similar age specific risk of $\mathrm{PD}$ for men and women, however, this study ascertained only subjects age

\begin{tabular}{ll} 
Table 2 & Age adjusted incidence ratio (men/women) \\
\hline Site & Age adjusted incidence ratio (M/F) \\
\hline Poland & 1.30 \\
China & 1.24 \\
Italy & 0.88 \\
Finland & 1.95 \\
Spain & 2.06 \\
US (MN) & 1.48 \\
US (NY) & 1.51 \\
median ratio $r_{\text {median }}$ & $1.49(95 \% \mathrm{CL}(1.24,1.95))^{*}$ \\
p(r $\left.r_{\text {median }} \leqslant 1\right)=0.0312$ &
\end{tabular}

*Confidence limits based on non-parametric bootstrap.
55 or older, thereby arbitrarily excluding a subpopulation of patients at risk for PD. Baldereschi et al recently reported PD incidence data from the Italian longitudinal study on aging (ILSA) ${ }^{16}$ The age adjusted average annual incidence rate was twice as high in men, but only 42 incident cases of PD were ascertained. The only study in our analysis reporting a male to female incidence ratio of less than 1 was that of Granieri et al, also from Ferrara in Italy. ${ }^{6}$ Baldereschi et al pointed out that their case finding methodology was superior to the record based strategy used by Granieri et al. The data reported by the ILSA group are particularly compelling because the investigators directly contacted the subjects in the general population and did not rely solely on medical records.

Thus, the best epidemiological datasets currently available consistently suggest that men are at greater risk for developing PD than are women. The reasons for the increased risk in men are not known. Is male sex in itself a risk factor for PD or is it a surrogate for some other primary risk factor to which men have greater exposure? For example, some casecontrol studies have suggested that toxicant exposure and head trauma may be risk factors for PD. ${ }^{1}$ Thus, the "male lifestyle" and certain sex roles that men assume such as farm work could account for some of the excess incidence in men. Alternatively, there is increasing evidence from in vitro as well as clinical studies in humans that oestrogen may be neuroprotective. ${ }^{17}$ The mechanisms whereby oestrogen may be neuroprotective may include activation of the mitogen activated protein kinase pathway, ${ }^{18}$ modulation of $\mathrm{Bcl}-\mathrm{x}(\mathrm{L})$ expression, ${ }^{19}$ and/or synergy with the free radical scavenger, glutathione. ${ }^{20}$ It may be relevant that the excess of PD in men, where mitochondrial dysfunction has been reported, ${ }^{21-23}$ is similar to the high ratio of affected men to women in Leber's hereditary optic neuropathy. ${ }^{24}$ Leber's hereditary optic neuropathy results from homoplasmic mutation of mitochondrial DNA encoding a portion of complex I of the mitochondrial electron transport chain; but, the mechanism for the increased risk of Leber's hereditary optic neuropathy in men is not known. Finally, several recent genetic linkage studies have localised a PD susceptibility gene to the $\mathrm{X}$ chromosome, a finding that could, potentially, explain the higher incidence of PD among men.25 Whatever the cause of increased risk of PD among men, a search for its basis may yield new clues to the pathogenesis of this enigmatic disease.

\footnotetext{
Authors' affiliations

G F Wooten, L J Currie, Department of Neurology, University of Virginia School of Medicine, Charlottesville, USA

V E Bovbjerg, J K Lee, J Patrie, Department of Health Evaluation Sciences, University of Virginia School of Medicine
} 
Competing interests: none declared

Correspondence to: Dr G F Wooten, Department of Neurology, Box 800394, University of Virginia Health System, Charlottesville, VA 22908, USA; gfw4b@virginia.edu

Received 17 June 2003

Revised 13 October 2003

Accepted 20 October 2003

\section{REFERENCES}

1 Tanner CM, Goldman SM. Epidemiology of Parkinson's disease. Neurol Clin 1996;14:317-35

2 Zhang Z, Roman GC. Worldwide occurrence of Parkinson's disease: an updated review. Neuroepidemiology 1993;12:195-208.

3 Tanner CM. Hubble JP. Chan P. Epidemiology and genetics of Parkinson's disease. In: Watts RL, Koller WC, eds. Movement disorders: neurologic principles and practice. New York: McGraw Hill, 1997:137-52.

4 Wender M, Pruchink D, Kowal P, et al. The epidemiology of parkinsonism in the Poznan region. Przegl Epidemiol 1989:43:150-5.

5 Wang YS, Shi YM, Wu ZY, et al. Parkinson's disease in China. Coordinated Group of Neuroepidemiology, PLA. Chinese Med J 1991;104:960-4.

6 Granieri E, Carresas M, Casetta I, et al. Parkinson's disease in Ferrara, Italy, 1967-1987. Arch Neurol 1991:48:854-7.

7 Kuopio A-M, Martilla RJ, Helenius $\mathrm{H}$, et al. Changing epidemiology of Parkinson's disease in southwest Finland. Neurology 1999:52:302-8.

8 Vines JJ, Larumbe R, Gaminde I, et al. Incidence of idiopathic and secondary Parkinson's disease in Navarre. Neurologia 1999;14:16-22.

9 Bower JH, Maragarore CM, McDonnell SK, et al. Incidence and distribution of parkinsonism in Olmstead County, Minnesota, 1976-1990. Neurology 1999;52:1214-20

10 Mayeux R, Marder K, Cote $\mathrm{L}$, et al. The frequency of idiopathic Parkinson's disease by age, ethnic group, and sex in Northern Manhattan, 1988-1993. Am J Epidemiol 1995;142:820-7.

11 Fleiss JL. Statistical methods for rates and proportions. 2nd edn. New York: Wiley, 1981.
12 Lehman EL. Nonparametrics: statistical methods based on ranks. San Francisco: Holden-Day, 1975.

13 Efron B, Tibshirani RJ. An introduction to the bootstrap. San Francisco: Chapman and Hall, 1993.

14 Rajput AH, Offord KP, Beard CM, et al. Epidemiology of parkinsonism: incidence, classification, and mortality. Ann Neurol 1984; 16:278-82.

15 Breteler MMB, De Rijk MC, OHt A, et al. Incidence of Parkinson's disease in a population-based study: the Rotterdam study. Neurology 1996;46(suppl 2):A332.

16 Baldereschi M, Di Carlo A, Rocca WA, et al. Parkinson's disease and parkinsonism in a longitudinal study: two-fold higher incidence in man. Neurology 2000;55:1358-63.

17 Inestrosa NC, Marzolo MP, Bonnefont AB. Cellular and molecular basis for estrogen's neuroprotection. Potential relevance for Alzheimer's disease. Mol Neurobiol 1998;17:73-86.

18 Singer CA, Figueroa-Mascot XA, Batchelor RH, et al. The mitogen-activated protein kinase pathway mediates estrogen neuroprotection after glutamate toxicity in primary cortical neurons. J Neurosci 1999; 19:2455-63.

19 Singer CA, Rogers KL, Dorsa DM. Modulation of BCL-2 expression-a potential component of estrogen protection in NT2 neurons. Neuroreport 1998;9:2565-8.

20 Green PS, Gridley KE, Simpkins JW. Nuclear estrogen receptor-independent neuroprotection by estratrienes - a novel interaction with glutathione. Neuroscience 1998;84:7-10.

21 Parker WD, Boyson SJ, Parks JK. Electron transport chain abnormalities in idiopathic Parkinson's disease. Ann Neurol 1989;26:719-23.

22 Schapira AHV, Cooper JM, Dexter D, et al. Mitochondrial complex I deficiency in Parkinson's disease. [Letter]. Lancet 1989;i:1289.

23 Mizuno Y, Ohta S, Tanaka M, et al. Deficiencies in complex I subunits of the respiratory chain in Parkinson's disease. Biochem Biophys Res Commun 1989;163:1450-5.

24 Oostra RJ, Kemp S, Bolhius PA, et al. No evidence for "skewed" inactivation of the X-chromosome as a cause of Leber's hereditary optic neuropathy in female carriers. Hum Genet 1996;97:500-5.

25 Pankratz N, Nichols WC, Uniacke SK, et al. Genome screen to identify susceptibility genes for Parkinson's disease in a sample without parkin mutations. Am J Hum Genet 2002;71:124-35. 